\title{
A comprehensive parameterization of heterogeneous ice nucleation of dust surrogate: laboratory study with hematite particles and its application to atmospheric models
}

\author{
N. Hiranuma ${ }^{1}$, M. Paukert ${ }^{1}$, I. Steinke ${ }^{1}$, K. Zhang ${ }^{2}$, G. Kulkarni ${ }^{2}$, C. Hoose ${ }^{1}$, M. Schnaiter ${ }^{1}$, H. Saathoff ${ }^{1}$, and \\ O. Möhler ${ }^{1}$ \\ ${ }^{1}$ Institute for Meteorology and Climate Research - Atmospheric Aerosol Research, Karlsruhe Institute of Technology, \\ Karlsruhe, Germany \\ ${ }^{2}$ Atmospheric Science and Global Change Division, Pacific Northwest National Laboratory, Richland, Washington, USA
}

Correspondence to: N. Hiranuma (seong.moon@kit.edu)

Received: 10 May 2014 - Published in Atmos. Chem. Phys. Discuss.: 24 June 2014

Revised: 1 October 2014 - Accepted: 28 October 2014 - Published: 10 December 2014

\begin{abstract}
A new heterogeneous ice nucleation parameterization that covers a wide temperature range $\left(-36\right.$ to $\left.-78^{\circ} \mathrm{C}\right)$ is presented. Developing and testing such an ice nucleation parameterization, which is constrained through identical experimental conditions, is important to accurately simulate the ice nucleation processes in cirrus clouds. The ice nucleation active surface-site density $\left(n_{\mathrm{s}}\right)$ of hematite particles, used as a proxy for atmospheric dust particles, were derived from AIDA (Aerosol Interaction and Dynamics in the Atmosphere) cloud chamber measurements under water subsaturated conditions. These conditions were achieved by continuously changing the temperature $(T)$ and relative humidity with respect to ice $\left(\mathrm{RH}_{\mathrm{ice}}\right)$ in the chamber. Our measurements showed several different pathways to nucleate ice depending on $T$ and $\mathrm{RH}_{\text {ice }}$ conditions. For instance, almost $T$-independent freezing was observed at $-60^{\circ} \mathrm{C}<T<-50^{\circ} \mathrm{C}$, where $\mathrm{RH}_{\text {ice }}$ explicitly controlled ice nucleation efficiency, while both $T$ and $\mathrm{RH}_{\text {ice }}$ played roles in other two $T$ regimes: $-78^{\circ} \mathrm{C}<T<-60^{\circ} \mathrm{C}$ and $-50^{\circ} \mathrm{C}<T<-36^{\circ} \mathrm{C}$. More specifically, observations at $T$ lower than $-60^{\circ} \mathrm{C}$ revealed that higher $\mathrm{RH}_{\text {ice }}$ was necessary to maintain a constant $n_{\mathrm{s}}$, whereas $T$ may have played a significant role in ice nucleation at $T$ higher than $-50{ }^{\circ} \mathrm{C}$. We implemented the new hematite-derived $n_{\text {s }}$ parameterization, which agrees well with previous AIDA measurements of desert dust, into two conceptual cloud models to investigate their sensitivity to the new parameterization in comparison to existing ice nucleation schemes for simulating cirrus
\end{abstract}

cloud properties. Our results show that the new AIDA-based parameterization leads to an order of magnitude higher ice crystal concentrations and to an inhibition of homogeneous nucleation in lower-temperature regions. Our cloud simulation results suggest that atmospheric dust particles that form ice nuclei at lower temperatures, below $-36^{\circ} \mathrm{C}$, can potentially have a stronger influence on cloud properties, such as cloud longevity and initiation, compared to previous parameterizations.

\section{Introduction}

Ice clouds represent a significant source of uncertainty when predicting Earth's climate change according to the recent Intergovernmental Panel on Climate Change report (i.e., Chapter 7 of IPCC 2013; Boucher et al., 2013). Rare airborne particles that can act as ice nucleating particles (INPs) at supercooled temperatures indirectly influence Earth's forcing by changing microphysical properties of ice clouds, such as reflectivity, longevity and precipitation. However, understanding ice cloud formation over a wide range of atmospherically relevant temperatures and humidity is challenging (e.g., DeMott et al., 2011; Murray et al., 2012), and our knowledge of ice formation through various nucleation modes is still scarce and limited, such that the ice nucleation processes are currently very poorly represented in global climate models (e.g., Hoose et al., 2010; Liu and Penner, 2005). In particu- 
lar, heterogeneous ice nucleation processes proceed through various modes including deposition nucleation, immersion, condensation and contact freezing (Chapter 9 of Pruppacher and Klett, 1997; Vali, 1985). Briefly, deposition mode induces ice formation when water vapor is directly deposited onto the INP, immersion and condensation freezing can induce ice formation when freezing is initiated by the INP immersed within the supercooled droplet or solution droplet, and contact freezing can initiate at the moment when an INP comes into contact with a supercooled droplet.

A global model simulation of INPs in tropospheric clouds showed that more than $85 \%$ of heterogeneous ice nucleation results from freezing of supercooled cloud droplets, in which INPs are either immersed or condensed (Hoose et al., 2010). However, freezing mechanisms in cirrus clouds are still uncertain (e.g., Sassen and Khvorostyanov, 2008). It is understood that various INPs can nucleate ice at water subsaturation and a range of supercooled temperature conditions as comprehensively illustrated in Fig. 2 of Hoose and Möhler (2012). The potential importance of ice nucleation under ice supersaturated conditions below the homogeneous freezing threshold line (i.e., Koop line; Koop et al., 2000; Ren and MacKenzie, 2005) has already been proven in earlier studies, suggesting the need for further investigations in the water subsaturated region. For example, Christenson (2013) experimentally showed that the capillary condensation of supercooled liquid on surface defects facilitated subsequent homogeneous nucleation and growth of ice below water saturation. Marcolli (2014) suggested that the inverse Kelvin effect below water saturation helps to form water in pores or cavities and hypothesized that this condensed water could freeze through the homogeneous- or immersion-mode freezing. This freezing mechanism was referred to as pore condensation and freezing. Previous laboratory studies introduced the concept of a freezing mechanism of solutions on particles at below water saturation (Zuberi et al., 2002; Hung et al., 2003; Archuleta et al., 2005). More recently, Welti et al. (2014) explored the relevance of soluble components of mineral dust (i.e., Fluka kaolinite) to condensation freezing below water saturation in the context of classical nucleation theory $(\mathrm{CNT})$. Furthermore, recent aircraftbased field observations suggested that predominant heterogeneous ice formation at cirrus temperatures occurs under water subsaturated conditions, in particular when $\mathrm{RH}_{\text {ice }}$ is below 140\% (Cziczo et al., 2013). In addition, Storelvmo and Herger (2014) demonstrated that forward modeling simulation with $50 \%$ of the mineral dust particles acting as INPs was in good agreement with an observation reported by $\mathrm{Cz}$ iczo et al. (2013). Another airborne observation during an Asian mineral dust event suggested that ice nucleation in cirrus clouds occurs under water subsaturation conditions below $130 \% \mathrm{RH}_{\text {ice }}$ (Sakai et al., 2014).

Previously, empirical descriptions given in Meyers et al. (1992; hereinafter referred to as M92) were derived from the limited field measurements of ice nu- clei concentrations measured at $-23{ }^{\circ} \mathrm{C}<T<-7{ }^{\circ} \mathrm{C}$ and $102 \%<\mathrm{RH}_{\text {ice }}<125 \%$. Recently, Phillips et al. (2008, 2013) empirically parameterized the heterogeneous ice nucleation of various types of aerosols as a function of humidity $\left(\mathrm{RH}_{\mathrm{ice}}>100 \%\right)$ and temperature conditions (0 to $\left.-100^{\circ} \mathrm{C}\right)$. Besides, CNT-based ice nucleation descriptions have also been widely used and implemented in cloud models (e.g., Barahona and Nenes, 2009a, b; Kärcher and Lohmann, 2003; Khvorostyanov and Curry, 2004). These parameterizations can predict different cloud properties for identical environmental conditions. For example, Barahona et al. (2010) showed that the ice crystal number can vary by up to an order of magnitude in a global chemical transport model depending on the choice of the heterogeneous ice nucleation parameterization. The authors found the lowest global mean ice crystal concentration from the parameterization of Phillips et al. (2008). Moreover, sensitivity of ice cloud properties to the parameterization was observed by Liu et al. (2012). They showed that the heterogeneous INP number concentration obtained from a CNT-based parameterization is typically higher by several factors than that of Phillips's parameterization under identical test conditions. To gain insight on what triggers such deviation and to constrain model uncertainties, more and better in situ measurements are necessary (Cziczo and Froyd, 2014). Specifically, identifying and quantifying sources, global spatiotemporal distribution and mixing state of INPs might help to reduce model assumptions. In parallel, systematic laboratory measurements are indeed needed to develop water subsaturated ice nucleation parameterizations for the range of atmospherically relevant $T$ and $\mathrm{RH}_{\text {ice }}$ conditions for a better representation of ice nucleation processes in cloud models and to support in situ measurements.

Recently, Hoose and Möhler (2012) compiled previously reported aerosol-specific heterogeneous freezing efficiencies from laboratory experiments based on a single parameter, $n_{\mathrm{s}}$ (e.g., Niemand et al., 2012; Connolly et al., 2009). In addition, the authors formulated ice nucleation efficiency by evaluating aerosol-specific "singular" freezing onsets when or after specific ambient conditions were met. Such timeindependent and surface-area-scaled $n_{\mathrm{s}}$ formulations can be further adapted to comprehensively assess the ice nucleation in a wide range of atmospherically relevant $T$ and $\mathrm{RH}_{\text {ice }}$ conditions. Accordingly, the $n_{\mathrm{s}}$ concept was adapted to deposition nucleation at low temperatures (up to $-80^{\circ} \mathrm{C}$ ).

Within the framework of the Ice Nuclei Research Unit (INUIT), we comprehensively investigated the ice nucleation efficiency of pristine cubic hematite particles as a model proxy for atmospheric dust particles. Hematite is used as an example of atmospheric mineral dust particles, which can also be found in the form of cloudborne particles in shallow stratocumulus clouds (Matsuki et al., 2010). Natural hematite often exists in supermicron-sized silt particles and accounts for a few percent of the total dust particle mass (Claquin et al., 1999). Ice nucleation efficiencies of cubic hematite particles were measured using the AIDA (Aerosol Interaction and 
Dynamics in the Atmosphere) cloud chamber. We also reexamined the previously reported AIDA results of hematite ice nucleation (Hiranuma et al., 2014; Skrotzki et al., 2013) and combined them with the results from this work in order to examine the ice nucleation efficiency of hematite particles in the temperature range between -36 and $-78^{\circ} \mathrm{C}$. In addition to developing the new dust parameterization from these AIDA measurements (Sects. 3.1-3.3), the fitted $n_{\text {s }}$ parameterization was also applied to atmospheric modeling simulations (Sect. 3.4). We implemented the parameterization in the Single-column version of the Community Atmospheric Model version 5 (SCAM5, Neale et al., 2010) and the Consortium for Small-scale Modeling (COSMO, Baldauf et al., 2011; Doms et al., 2011) models to assess the newly developed parameterization and compare them with existing parameterizations. It is important to note that the purpose of the current study is to perform a conceptual study with laboratory-synthesized hematite particles as a model aerosol for deposition ice nucleation, over a wide range of $T$ and $\mathrm{RH}_{\text {ice }}$, but not to quantify how much hematite content contributes to ice formation in cirrus clouds.

\section{Method}

\subsection{Description of hematite particles}

Laboratory-generated cubic hematite particles that have homogeneous chemico-physical properties were used as a proxy for atmospheric dust particles. These particles had a uniform composition, morphology and well-defined surface area. Hence, they are suited well for investigating $T$ - and $\mathrm{RH}_{\text {ice }}$-dependent ice nucleation efficiency and relating it to the surface area (Hiranuma et al., 2014). Detailed information on the manufacturing process of cubic hematite particles is available elsewhere (Sugimoto and Sakata, 1992). Three different sizes of quasi-monodispersed hematite particles ( $\sim 200, \sim 500$ and $\sim 1000 \mathrm{~nm}$ diameter, respectively) were used in this work. The morphology and size of the hematite particles were characterized by scanning electron microscopy and determined based on an equivalent circle diameter derived from the observed 2-D particle projection area (Vragel, 2009; Hiranuma et al., 2014). A small-scale powder disperser (SSPD, TSI, Model 3433) was used to drydisperse the quasi-monodispersed hematite particles into the AIDA vessel as demonstrated in Skrotzki et al. (2013).

\subsection{AIDA cooling expansion}

The AIDA expansion freezing experiments were achieved by mechanical pumping (Möhler et al., 2003). Mechanical pumps can be operated at different pumping speeds simulating atmospherically relevant adiabatic cooling of rising air parcels in the cylinder of $84 \mathrm{~m}^{3}$ in volume (i.e., $7 \mathrm{~m}$ height $\times 4 \mathrm{~m}$ width thermally conductive aluminum vessel) installed inside the thermostatic housing. For this study, a cooling rate of $5^{\circ} \mathrm{C} \mathrm{min}-1$ was typically applied at the beginning. Then, the cooling rate decreased to $<0.1^{\circ} \mathrm{C} \mathrm{min}^{-1}$ within $400 \mathrm{~s}$ for each pumping expansion experiment, which was mainly due to an increasing heat flux from the chamber walls. Afterwards, an almost constant temperature was maintained by the stirred and well-mixed volume of the cold chamber. During the experiment, the pressure in the vessel decreased from 1000 to $800 \mathrm{mb}$.

The mean gas temperature in the AIDA vessel was determined by five thermocouples installed at different vertical levels. The sensors of these thermocouples were located about $1 \mathrm{~m}$ off the vessel wall and, thus, fully exposed to the chamber air. Stirring of the air by the mechanical ventilator prior to and during pumping ensured a homogeneous temperature distribution in the vessel of $\pm 0.3^{\circ} \mathrm{C}$ (Möhler et al., 2003). The relative humidities with respect to water $\left(\mathrm{RH}_{\text {water }}\right)$ and $\mathrm{RH}_{\text {ice }}$ were determined with an accuracy of $\pm 5 \%$ using the mean gas temperature and the mean water vapor concentration. The water vapor concentrations were measured in situ by tunable diode laser (TDL) water vapor absorption spectroscopy throughout the expansion experiments. Since this direct long-path absorption technique is described and evaluated in detail in other publications ( $\mathrm{Fa}$ hey et al., 2014; Skrotzki et al., 2013), no further information is given here.

Under atmospheric pressure, prior to each expansion experiment, a combination of a scanning mobility particle sizer (SMPS, TSI, Model 3080 differential mobility analyzer and Model 3010 condensation particle counter), an aerosol particle sizer (APS, TSI, Model 3321) and a condensation particle counter (CPC, TSI, Model 3076) collectively measured the total number and size distribution of aerosols at the horizontally extended outlet of the AIDA chamber. Subsequently, the total aerosol surface area was estimated as presented in Hiranuma et al. (2014). During expansion, we quantified the ice nucleation of hematite particles with two different light scattering instruments: an optical particle counter welas (PALAS, Sensor series 2300 and 2500) (Benz et al., 2005) and SIMONE (German acronym of Streulichtintensitätsmessungen zum optischen Nachweis von Eispartikeln, which translates to the scattering intensity measurement for the optical detection of ice; Schnaiter et al., 2012). More details on the application of this specific combination of two instruments for the AIDA ice nucleation experiments are given in Hiranuma et al. (2014).

\subsection{Ice nucleation parameterization and modeling}

The size-independent singular ice nucleation efficiency, $n_{\mathrm{s}}$, was calculated by normalizing the observed AIDA ice crystal concentration $\left(N_{\text {ice }}\right)$ to the total surface area of aerosols, which can be calculated by multiplying the surface area of an individual particle $\left(S_{\mathrm{i}}\right)$ by the total number concentration of aerosols $\left(N_{\mathrm{ae}}\right)$ (e.g., Niemand et al., 2012; Hoose and Möhler, 2012). For size-selected hematite particles, 
this linear approximation (i.e., $\left.n_{\mathrm{s}}=(-\ln (1-\alpha)) / S_{\mathrm{i}} \sim \alpha / S_{\mathrm{i}}\right)$ was mostly valid for the observed ice number fraction ( $\alpha=N_{\text {ice }} / N_{\mathrm{ae}}$ ). An overestimation of ice due to the use of linear approximation only amounted up to about a factor of 3 at $n_{\mathrm{s}} \leq 10^{12} \mathrm{~m}^{-2}$. Subsequently, the $n_{\mathrm{s}}$ values estimated for the wide range of experimental conditions $\left(-36^{\circ} \mathrm{C}<T<-78^{\circ} \mathrm{C}\right.$ and $100 \%<\mathrm{RH}_{\text {ice }}<$ water saturation) were used to depict and fit constant $n_{\mathrm{S}}$ contour lines. Here, these lines are referred to as the $n_{\mathrm{s}}$ isolines or simply as the isolines.

The isoline-based parameterizations were derived (see Sect. 3.3) and then implemented in two atmospheric models (a single-column version of a global-scale model and a convection resolving model; see Sects. 2.3.1. and 2.3.2. for model descriptions). The unique advantages of the use of both models in this study are (1) to demonstrate that our AIDA $n_{\mathrm{s}}$-based parameterization can be directly applied on different scales of atmospheric models and (2) to estimate the number of ice crystals simulated in two different atmospheric scenarios that complement each other and cover a wide range of atmospheric temperature and saturation conditions (ice formation at higher $\mathrm{RH}_{\text {ice }}$, up to $\sim 180 \%$, and lower $T$, down to $\sim-70^{\circ} \mathrm{C}$ ). More specifically, the former represents a finely resolved parameterization-oriented model embedded in the global model while the latter is a more physically based high-resolution grid-scale model, typically used to analyze small-scale complex systems for a fundamental understanding of ice formation. Altogether, results from two independent models were examined for a detailed modeling of atmospheric ice formation on all scales.

The mean size and surface area of hematite particles were prescribed with an assumption that either these particles are spherical and have a mean particle diameter of $1000 \mathrm{~nm}$ or the size of these particles follows a log-normal distribution, with a mean volume-equivalent diameter of $\sim 1000 \mathrm{~nm}$ $\left(\sigma_{\mathrm{g}}=1.05\right)$, which is consistent with the AIDA experiments described earlier (Hiranuma et al., 2014). The cloud microphysical sensitivity of these two size treatments was characterized. In addition, the sensitivity simulations of two lower boundaries of $\mathrm{RH}_{\text {ice }}$ (i.e., 100 vs. $105 \%$ ) were also carried out. This sensitivity analysis was specifically useful to examine uncertainty involved in the TDL measurement $\left(\mathrm{RH}_{\text {ice }} \pm 5 \%\right)$ concerning the condensed $n_{\mathrm{s}}$ spacing (up to several orders of magnitude) in a narrow $\mathrm{RH}_{\text {ice }}$ range and a certain $T$ region. In both models, hematite particle number concentrations are given to be $200 \mathrm{~L}^{-1}$, which is about the average dust concentration simulated by the SCAM5 model over the Southern Great Plain (SGP) site in springtime. Since the $n_{\mathrm{s}}$-isoline parameterization tested in this study is applicable at $T$ below $-36^{\circ} \mathrm{C}$, an additional parameterization was used to simulate ice formation of background particles at $T>-36{ }^{\circ} \mathrm{C}$, namely, the aerosol-independent M92 scheme. These parameterizations were combined to ensure more atmospherically relevant processes and conditions (e.g., distri- butions of water vapor) when compared to the application of the $n_{\mathrm{s}}$-isoline parameterization alone.

To better understand to what an extent the AIDA $n_{\mathrm{s}^{-}}$ based parameterization differs from other parameterizations commonly used in atmospheric models, the existing empirical parameterization of heterogeneous ice nucleation by Phillips et al. (2013; hereinafter denoted as P13) was implemented as well. The P13 scheme reflects the aerosol specific ice nucleation. In particular, the contribution of mineral dust with the background troposphere baseline surface area mixing ratio of ice-nucleating mineral dust particles (i.e., $2.0 \times 10^{-6} \mathrm{~m}^{2} \mathrm{~kg}^{-1}$ ) was considered in this study. Ice formation occurring below water saturation only was considered and, thus, Eq. (1) in Phillips et al. (2008) was used for parameterizing ice nucleation.

\subsubsection{SCAM5}

Single-column models are widely used to test physical parameterizations for use in the general circulation model (GCM). The model has 30 vertical levels, and the model time step is set to $10 \mathrm{~min}$. The single-column model resembles a single column of a GCM and can be derived from observations or model output. The complex feedbacks between the simulated column and other columns due to large-scale dynamics are not considered. Therefore, the single-column model is an ideal tool for testing ice cloud parameterizations. The SCAM5 model was modified to incorporate the new parameterization developed in this study. The Barahona and Nenes $(2008,2009 a$, b) scheme, which provides an analytical solution of the cloud parcel model equations (hereinafter called BN scheme), is used for calculating ice nucleation in cirrus clouds. The new AIDA $n_{\mathrm{s}}$-isoline-based parameterizations as well as the P13 scheme were implemented in the model. The simulation was performed for 1 month (April 2010) at the United States Department of Energy's Atmospheric Radiation Measurement facility located at the SGP site (Hiranuma et al., 2014).

\subsubsection{COSMO}

The nonhydrostatic weather forecast model, COSMO, was adapted to systematically investigate the impact of hematite particles under the simulated upper-tropospheric conditions. COSMO is the high-resolution limited-area model to assess clouds and convection at a horizontal spatial resolution of $2.8 \mathrm{~km}$ with 50 layers of stretched vertical grids. The time step is set to $20 \mathrm{~s}$. In this study, we simulated a period of 2 days (23-25 July 2011) on a domain of $450 \times 450$ horizontal grid points centered over the German Alps (longitude: $0.1-18.7^{\circ} \mathrm{E}$, latitude: $\left.41.7-53.2^{\circ} \mathrm{N}\right)$. The initial and boundary conditions were provided by the European Centre for Medium-Range Weather Forecasts. They are available at the Meteorological Archival and Retrieval System. In order to account for the spatiotemporal evolution of mass 
Table 1. Summary of aerosol measurements and AIDA ice nucleation experiments. All HALO experiments are from Skrotzki et al. (2013).

\begin{tabular}{|c|c|c|c|c|c|c|c|c|}
\hline \multirow[b]{2}{*}{ Experiment ID } & \multicolumn{3}{|c|}{ Aerosol measurements } & \multicolumn{5}{|c|}{ Ice nucleation measurements } \\
\hline & $\begin{array}{l}\text { Hematite } \\
\text { diameter, } \\
\mathrm{nm}\end{array}$ & $\begin{array}{l}\text { Total } \\
\text { number } \\
\text { conc., } \\
\mathrm{cm}^{-3}\end{array}$ & $\begin{array}{l}\text { Total } \\
\text { surface } \\
\text { conc., } \\
\mu \mathrm{m}^{2} \mathrm{~cm}^{-3}\end{array}$ & $\begin{array}{l}\text { Examined } \\
T \text { range, }{ }^{\circ} \mathrm{C}\end{array}$ & $\begin{array}{l}\text { Examined } \\
\mathrm{RH}_{\text {ice }} \\
\text { range, \% }\end{array}$ & $\begin{array}{l}\text { Evaluated } \\
n_{\mathrm{s}}, \mathrm{m}^{-2}\end{array}$ & $\begin{array}{l}T \text { (evaluated } \\
\left.n_{\mathrm{S}}\right),{ }^{\circ} \mathrm{C}\end{array}$ & $\begin{array}{l}\mathrm{RH}_{\text {ice }} \\
\text { (evaluated } \\
n_{\mathrm{S}} \text { ), \% }\end{array}$ \\
\hline HALO05_24 & 200 & 115.0 & 14.4 & -76.1 to -81.9 & 100.6 to 164.8 & $10^{11}$ & -78.2 & 136.4 \\
\hline HALO04_09 & 500 & 112.5 & 26.9 & -75.8 to -80.1 & 100.3 to 149.8 & $10^{11}$ & -77.5 & 128.3 \\
\hline HALO04_05 & 500 & 142.2 & 30.9 & -61.8 to -65.5 & 100.2 to 135.6 & $10^{11}$ & -62.6 & 111.1 \\
\hline HALO05_18 & 200 & 161.9 & 21.8 & -60.3 to -65.2 & 100.1 to 124.5 & $10^{11}$ & -60.8 & 106.0 \\
\hline HALO06_22 & 200 & 145.7 & 19.2 & -50.2 to -53.9 & 100.3 to 123.4 & $10^{11}$ & -50.7 & 106.7 \\
\hline HALO06_21 & 200 & 245.0 & 32.9 & -50.3 to -53.8 & 100.4 to 115.8 & $10^{11}$ & -50.5 & 102.2 \\
\hline INUIT01_26 & 1000 & 342.1 & 749.0 & -41.0 to -47.1 & 100.2 to 103.9 & $10^{10}$ & -41.2 & 102.2 \\
\hline HALO06_20 & 200 & 168.7 & 22.4 & -39.8 to -44.4 & 100.4 to 128.8 & $10^{10}$ & -40.7 & 111.3 \\
\hline HALO06_19 & 200 & 283.0 & 42.9 & -39.7 to -44.5 & 100.2 to 121.6 & $10^{10}$ & -40.6 & 109.2 \\
\hline INUIT04_08 & 1000 & 193.0 & 647.0 & -39.3 to -45.4 & 100.0 to 113.2 & $10^{10}$ & -40.4 & 110.1 \\
\hline INUIT04_10 & 1000 & 161.7 & 546.6 & -37.5 to -43.7 & 100.0 to 124.1 & $10^{10}$ & -40.1 & 123.3 \\
\hline INUIT01_30 & 1000 & 414.5 & 889.7 & -34.6 to -42.0 & 100.2 to 127.1 & $2.5 \times 10^{8}$ & -37.0 & 122.8 \\
\hline
\end{tabular}

and number densities of six hydrometeor classes (i.e., cloud droplets, raindrops, cloud ice, snow, graupel and hail), the two-moment bulk microphysics scheme was incorporated in our COSMO model version following the method described by Seifert and Beheng (2006) and Seifert et al. (2012). Apart from the AIDA isoline-based freezing parameterization of hematite, two other ice nucleation modes, namely, M92 and homogeneous nucleation of cloud or solution droplets (Kärcher et al., 2006; Ren and MacKenzie, 2005), were considered in our COSMO simulations. The latter was used to parameterize the competition of water vapor between homogeneous and heterogeneous freezing.

\section{Results}

\subsection{AIDA ice nucleation experiments}

A series of AIDA experiments was carried out during the INUIT01 and INUIT04 campaigns to investigate the ice nucleation efficiency of well-characterized hematite particles under water subsaturated conditions at $-47^{\circ} \mathrm{C}<T$. In addition, we used the AIDA results reported by Skrotzki et al. (2013) and reconciled them with the $n_{\mathrm{s}}$ values in order to parameterize the overall ice nucleation efficiency of hematite particles up to $-78^{\circ} \mathrm{C}$. In total, 12 expansion experiments, 4 from the INUIT campaigns and 8 from Skrotzki et al. (2013), were studied. Detailed experimental conditions and aerosol properties for these expansion experiments are summarized in Table 1 . The use of different sizes of hematite particles in different temperature regions was justified by calculating the size-independent $n_{\mathrm{S}}$ values of 200 and $1000 \mathrm{~nm}$ diameter particles at $\sim-40^{\circ} \mathrm{C}$. For instance, the evaluated $n_{\mathrm{s}}$ values $\left(10^{10} \mathrm{~m}^{-2}\right)$ for these two sizes agreed very well within $\pm 1 \% \mathrm{RH}_{\text {ice }}$ and $\pm 0.3^{\circ} \mathrm{C}$ of chamber con- ditions (see corresponding $\mathrm{RH}_{\mathrm{ice}}$ and $T$ at "Evaluated $n_{\mathrm{s}}$ " in Table 1 for INUIT04_08, $1000 \mathrm{~nm}$, HALO06_19, $200 \mathrm{~nm}$, and HALO06_20, 200 nm). This agreement verified the reproducibility of the AIDA chamber experiments, ice nucleation efficiency of hematite particles and size independence of the $n_{\mathrm{s}}$ calculations. The advantage of using $1000 \mathrm{~nm}$ diameter hematite particles was that, due to their comparatively larger surface area, they were efficient in forming ice in cooling expansion experiments at $-40^{\circ} \mathrm{C}<T<-36^{\circ} \mathrm{C}$ (Hiranuma et al., 2014).

The temporal profiles of deposition nucleation experiments from HALO campaigns, including $N_{\text {ice }}$, gas $T, \mathrm{RH}_{\text {ice }}$ and $\mathrm{RH}_{\text {water }}$ measured by the TDL as well as the polarized light scattering properties in near-backscattering direction measured by SIMONE, are shown in Fig. 1. The depolarization ratio, which is sensitive to ice particle nucleation and growth, can be deduced from the latter. During a typical expansion, the air mass in the vessel experiences continuous cooling (for up to $500 \mathrm{~s}$ ) and an increase in relative humidity (for up to $200 \mathrm{~s}$; Fig. 1i, ii). Figure 1iii shows the temporal plot of the depolarization ratio. At the beginning of the expansion, the depolarization ratio increases because ice is nucleating on the hematite particles. Conversely, repartitioning of gas-phase water to ice-phase water due to growing ice crystals triggers the declines in both depolarization ratio (i.e., sizing effect, Schnaiter et al., 2012) and RH, usually after $100 \mathrm{~s}$. The time delay in our welas ice detection (typically $1 \mu \mathrm{m}$ is the minimum ice detection diameter for 200 and $500 \mathrm{~nm}$ diameter hematite particles) due to slower depositional growth after ice nucleation at lower $T$ is accounted for in our error analyses (Fig. 2). We evaluated only up to several hundred seconds of each expansion experiment as the ice nucleating period. Similar experimental profiles for INUIT campaigns are presented in Fig. S1 in the Supplement. 

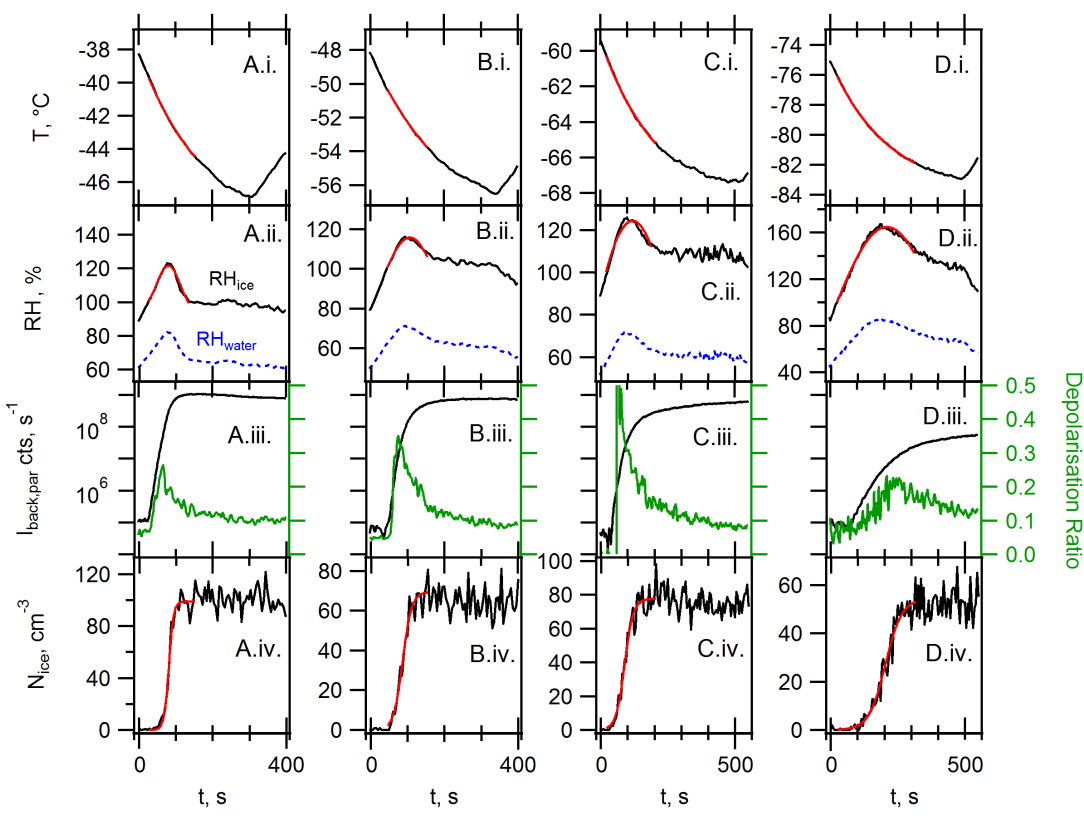

Figure 1. Temporal plots of the representative AIDA deposition-mode freezing experiments with various cooling ranges, including A. HALO06_19, B. HALO06_21, C. HALO05_18 and D. HALO05_24. Panels are arranged to show the measurements of i. AIDA mean gas temperature $(T)$, ii. TDL, iii. SIMONE and iv. ice crystal concentration $\left(N_{\text {ice }}\right)$. Note that the red lines represent interpolated data used for the $n_{\mathrm{s}}$-isoline formulation. The $\mathrm{I}_{\mathrm{back}}$,par in the panel iv axis denotes the backscattered light scattering intensity parallel to the incident polarization state (log-scaled). An increase in the depolarization ratio indicates the formation and growth of ice crystals.

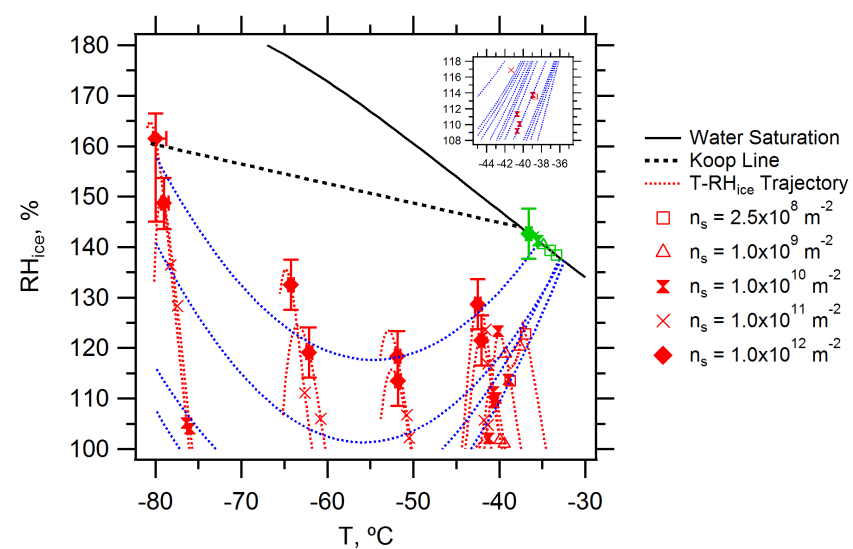

Figure 2. The constant $n_{\mathrm{S}}$ magnitudes are joined by lines (blue) representing "isolines" of hematite freezing profiles in the $T$ and $\mathrm{RH}_{\text {ice }}$ space. The interpolated isolines are equally spaced at every order of magnitude from $10^{12} \mathrm{~m}^{-2}$ (top) to $10^{9} \mathrm{~m}^{-2}$ (bottom). Experimental trajectories of AIDA expansion experiments with hematite particles are shown as red dotted lines. The data indicated with green color on the water saturation line represent the previously reported results of immersion freezing (Hiranuma et al., 2014). The subpanel shows a magnified section of $T\left(-35\right.$ to $\left.-45^{\circ} \mathrm{C}\right)$ and $\mathrm{RH}_{\text {ice }}$ (110-120\%) space with equidistant $n_{\mathrm{S}}$ spacing (every quarter magnitude). The error bars at $n_{\mathrm{s}}$ of $10^{12} \mathrm{~m}^{-2}$ are from welas.
The initial $n_{\mathrm{s}}$-isoline curves in the $T$ and $\mathrm{RH}_{\text {ice }}$ space are illustrated in Fig. 2. Constant $n_{\mathrm{s}}$-isoline curves are obtained by fitting second-degree polynomial fit equations to the constant $n_{\mathrm{s}}$ magnitudes calculated at various $T$ and $\mathrm{RH}_{\text {ice }}$ (see the Supplement for more details). Previous AIDA results of two immersion freezing experiments (i.e., INUIT04_13 and INUIT01_28 from Hiranuma et al., 2014) are also shown on the water saturation line and used to constrain the fitted curves because immersion freezing is considered part of the isolines. Since the $n_{\mathrm{S}}$ values presented in Fig. 3 of Hiranuma et al. (2014) only extend up to $\sim 10^{9} \mathrm{~m}^{-2}$, the data points of higher $n_{\mathrm{s}}$ values were extrapolated based on the observed values from two measurements. Figure 2 shows several important features of $n_{\mathrm{s}}$-isoline curves. First, below $-60^{\circ} \mathrm{C}$, $n_{\mathrm{s}}$ isolines showed an increase in $\mathrm{RH}_{\text {ice }}$ required to maintain a constant $n_{\mathrm{s}}$ (i.e., $n_{\mathrm{S}}>2.5 \times 10^{8} \mathrm{~m}^{-2}$ ) with decreas-

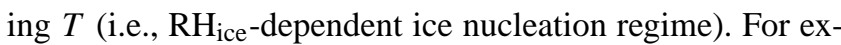
ample, at $\mathrm{RH}_{\text {ice }}=120 \%$ and $T=-75^{\circ} \mathrm{C}$, cooling by $1{ }^{\circ} \mathrm{C}$ corresponds to a $10 \%$ decrease in $n_{\mathrm{s}}$. This observation is interesting because the increase in $\mathrm{RH}_{\text {ice }}$ required to maintain constant $n_{\mathrm{S}}$ values is consistent with the CNT for deposition nucleation (Eq. A11 in Hoose and Möhler, 2012). Second, the highest sensitivity of $\mathrm{RH}_{\text {ice }}$ is observed in a region where $n_{\mathrm{S}}$ isolines are perpendicular to temperature isolines $\left(\sim-60^{\circ} \mathrm{C}<T<\sim-50^{\circ} \mathrm{C}\right)$. Here, $n_{\mathrm{S}}$ is almost independent of $T$, and solely dependent on $\mathrm{RH}_{\text {ice }}$. Finally, we observed strong $T$-dependent nucleation near water saturation (i.e., while cooling along the water saturation line to- 


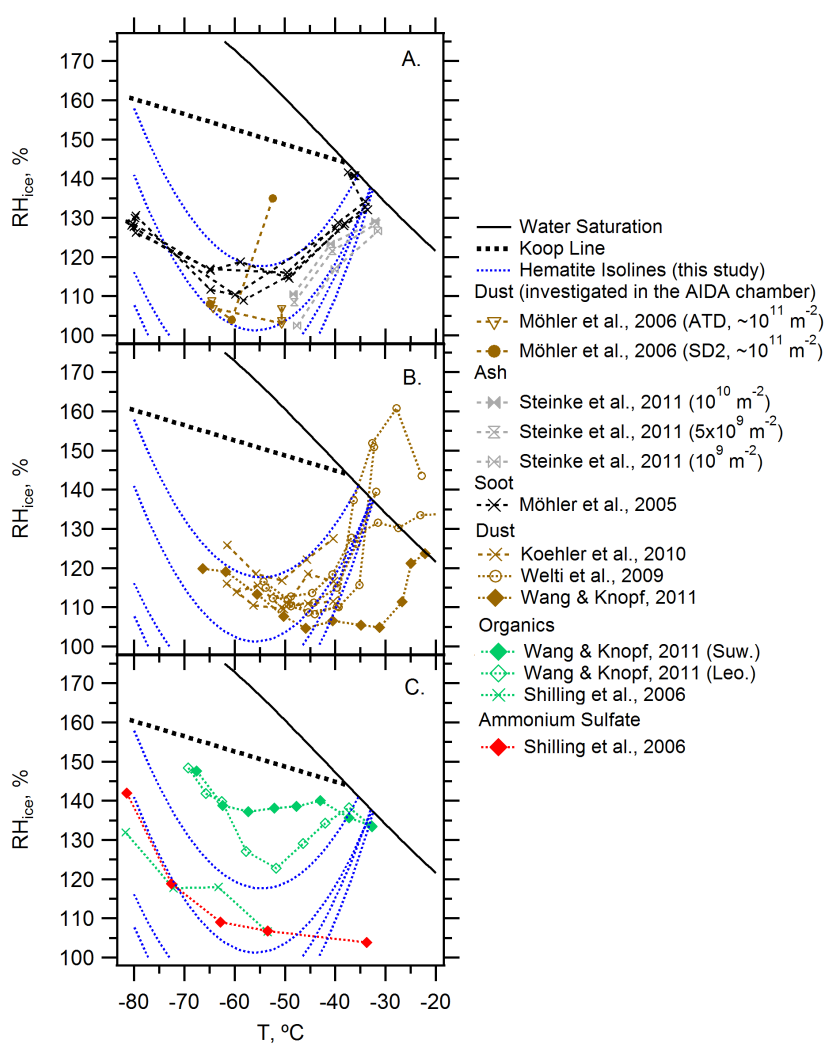

Figure 3. Ice nucleation onset $T$ and $\mathrm{RH}_{\text {ice }}$ of previously published data (a AIDA studies, $\mathbf{b}$ dust, and $\mathbf{c}$ ammonium sulfate and organics) shown together with the isolines of hematite particles from the present study $\left(10^{12} \mathrm{~m}^{-2}\right.$ (top) $-10^{9} \mathrm{~m}^{-2}$ (bottom)).

wards $\sim-50^{\circ} \mathrm{C}$ ). At a constant $\mathrm{RH}_{\text {ice }}$ (e.g., $114 \%$ ), for example, cooling by $1{ }^{\circ} \mathrm{C}$ from -41 to $-42^{\circ} \mathrm{C}$ corresponds to an increase in $n_{\mathrm{S}}$ of approximately half an order of magnitude (see inset in Fig. 2). This suggests that the $n_{\mathrm{s}}$ values depend on temperature. Interestingly, we observed a continuous increase in $n_{\mathrm{S}}$ during cooling even after the depletion of supersaturation below $-40^{\circ} \mathrm{C}$ (Fig. S2 in the Supplement). CNT does not explain this predominant $T$ contribution near water saturation (Fig. A1 in Hoose and Möhler, 2012). Therefore, other microphysical processes at the particle surface and/or perhaps even within the bulk phase may be responsible for this $T$-dependent behavior and these results appear to support the existence of a pore- or surface-freezing process, as discussed in recent literature (e.g., Marcolli, 2014). In particular, we suspect that water condensation on the particle surface plays an important role on subsequent freezing. To support this, the surfaces of our hematite particles are not perfectly smooth and contain some active sites (e.g., pores and steps; Hiranuma et al., 2014). Moreover, water vapor may preferably fill the surface cavities due to the reduced saturation pressure in pores or at steps because of negative curvature Kelvin effects (Marcolli, 2014), thus leading to namely "surface condensation freezing" (SCF). As described in pre- viously published literatures (Christenson, 2013; Marcolli, 2014), SCF may be of relevance to homogeneous nucleation (i.e., spontaneous ice nucleation in supercooled aerosol) at relevant $T\left(<-36^{\circ} \mathrm{C}\right)$ and/or immersion mode freezing under water subsaturated conditions. Thus, SCF may arise from both homogeneous and heterogeneous nucleation.

\subsection{Comparison with previous studies}

The $n_{\mathrm{s}}$ isolines of hematite particles were compared to previous measurements made using different aerosol species. This comparison was performed to (1) confirm that our $n_{\mathrm{s}}$ fit reproduces the overall trend shown by previous studies under certain $T$ and $\mathrm{RH}_{\text {ice }}$ conditions and (2) to demonstrate that the parameterization with laboratory-synthesized hematite particles quantitatively represents ice nucleation properties of atmospheric dust particles.

Comparison of the hematite $n_{\mathrm{s}}$ isolines to previous deposition freezing observations are shown in Fig. 3. More specifically, previous measurements were performed with natural Saharan desert dust (SD2, Möhler et al., 2006), reference Arizona test dust (ATD, Möhler et al., 2006; Welti et al., 2009), volcanic ash (Steinke et al., 2011), soot (Möhler et al., 2005), clay minerals (Welti et al., 2009; Koehler et al., 2010) and organics (Shilling et al., 2006; Wang and Knopf, 2011). These previous experimental studies used various types of ice nucleation instruments, such as substrate-supported cold stages coupled with an optical microscope (Shilling et al., 2006; Wang and Knopf, 2011), portable ice nuclei counters (Koehler et al., 2010; Welti et al., 2009) and the AIDA cloud simulation chamber (Möhler et al., 2005; Möhler et al., 2006; Steinke et al., 2011). They revealed the importance of both $\mathrm{RH}_{\text {ice }}$ and temperature onto deposition-mode ice nucleation of specific particle compositions. In Fig. 3a, previous AIDA results for dusts, ash and soot are presented. Specifically, we utilized the $T$ and $\mathrm{RH}_{\text {ice }}$ data at $\alpha=0.08$ of SD2 and ATD reported in the previous AIDA study (Möhler et al., 2006) to define isolines. It is noteworthy that an $\alpha$ of 0.08 corresponds to $\sim 10^{11} \mathrm{~m}^{-2}$ in $n_{\mathrm{s}}$ when assuming uniform distributions of spherical particles of $0.5 \mu \mathrm{m}$ diameter $\left(n_{\mathrm{s}}=(-\ln (1-\right.$ $\left.\alpha)) /\left(\pi\left(0.5 \times 10^{-6}\right)^{2}\right)\right)$, which is in good agreement with the $10^{11} \mathrm{~m}^{-2} n_{\mathrm{s}}$-isoline of hematite particles. For volcanic ash, we adapted $n_{\mathrm{s}}$ values $\left(10^{9}, 5 \times 10^{9}\right.$ and $\left.10^{10} \mathrm{~m}^{-2}\right)$ originally reported in Steinke et al., (2011). Möhler et al. (2005) found that the ice nucleation of soot starts at the initial increase in polarized light scattering intensity in near-backscattering direction at $488 \mathrm{~nm}\left(n_{\mathrm{s}}\right.$ values are inaccessible). Except for these AIDA studies, other isolines in Fig. 3b and c were defined based on the reported ice nucleation measurements. For instance, Koehler et al. (2010) studied the deposition-mode nucleation of size-selected (i.e., 200, 300, $400 \mathrm{~nm}$ ) natural dusts, and reported ice nucleation conditions ( $T$ and $\mathrm{RH}_{\text {ice }}$ ) of ATD at $\alpha=0.01$ and of Canary Island dust and Saharan dust at $\alpha=0.05$. Welti et al. (2009) also studied the deposition nucleation abilities of size-segregated mineral dusts (i.e., 

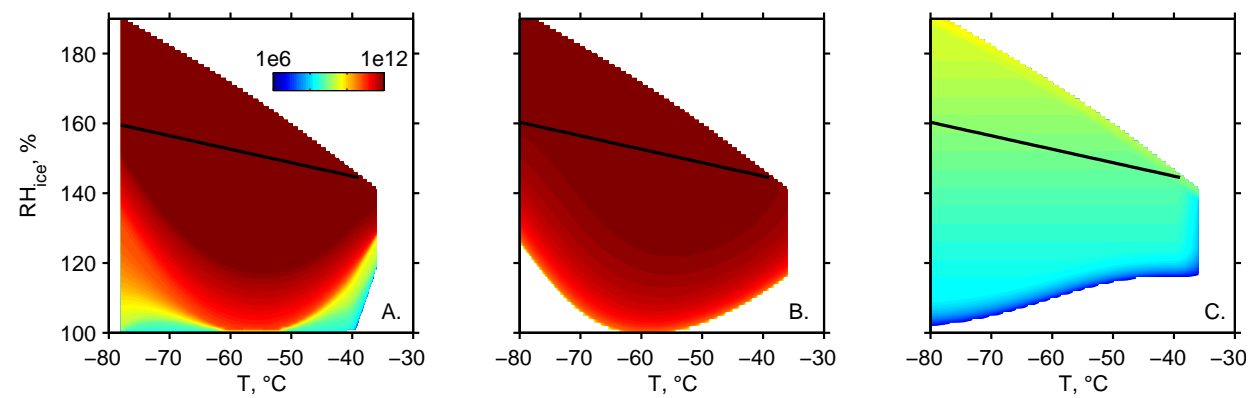

Figure 4. Spatial plot of isolines for constant $n_{\mathrm{S}}$ derived from (a) interpolating AIDA data, (b) applying the third-degree-polynomial fit function to interpolated AIDA data, and (c) a previously published parameterization (Phillips et al., 2013) for hematite particles. The color scale displays $\log$-scaled $n_{\mathrm{S}}$ values per square meter, applicable to all panels. The solid black lines indicate the homogeneous freezing threshold line (i.e., Koop line).

100-800 nm diameter of ATD, illite, kaolinite and montmorillonite) based on $\alpha=0.01$. Shilling et al. (2006) reported the ice nucleation onsets of ammonium sulfate and maleic acid detected by the decreasing partial pressure of water with FTIR-reflection absorption spectroscopy (e.g., 1 in $10^{5}$ nucleation at about $-33{ }^{\circ} \mathrm{C}$ for a spherical particle size of $1-$ $10 \mu \mathrm{m}$ diameter). Wang and Knopf (2011) investigated deposition freezing of various mineral and organic particles including kaolinite, Suwannee River standard fulvic acid and Leonardite standard humic acid particles. The authors reported the mean size of particles and associated ice-activated fractions at the given $T$ and $\mathrm{RH}_{\text {ice }}$.

As seen in Fig. 3, the results from previous studies suggest the necessity of increasing $\mathrm{RH}_{\text {ice }}$ to maintain a constant $n_{\mathrm{s}}$ value below $T \sim-55^{\circ} \mathrm{C}$. They also indicate that nucleation may be triggered by SCF in the region where data and isolines approach water saturation where temperature plays a significant role on ice nucleation. It can also be observed that the contour of our new $n_{\mathrm{s}}$-isoline parameterization of cubic hematite particles in $T$ and $\mathrm{RH}_{\text {ice }}$ coordinates generally agrees with the onsets determined by previous studies of other atmospherically relevant aerosols. In particular, the $n_{\mathrm{s}}$ isolines estimated from ATD and SD2 $\left(\sim 10^{11} \mathrm{~m}^{-2}\right.$; Fig. 3a), which reasonably agree with the hematite $n_{\mathrm{s}}$-isoline, suggest that atmospheric dust may have similar deposition-mode ice nucleation efficiency.

\section{3 $\quad n_{\mathrm{s}}$-isoline-based parameterizations}

Next, the ice nucleation efficiency of hematite particles was parameterized over a wide range of $T$ and $\mathrm{RH}_{\text {ice. }}$. Three types of parametrical descriptions used in this study are shown in Fig. 4. First, based on the AIDA experimental results, a series of constant $n_{\mathrm{S}}$ curves was interpolated to produce isolines in the range of $10^{6} \mathrm{~m}^{-2}<n_{\mathrm{s}}<10^{12} \mathrm{~m}^{-2}$ (Fig. 4a). The lower bound of the $n_{\mathrm{s}}$ value $\left(10^{6} \mathrm{~m}^{-2}\right)$ was set based on the minimum $n_{\mathrm{s}}$ observed during AIDA expansions. Since the certain regions of $n_{\mathrm{s}}$ isolines (i.e., $n_{\mathrm{s}}<7.5 \times 10^{10} \mathrm{~m}^{-2}$; blue lines in Fig. 2) can submerge below ice saturation, the correction was applied to shift them and maintain all isolines above $100 \% \mathrm{RH}_{\text {ice. }}$. The procedure to constrain $n_{\mathrm{s}}$ to $>100 \% \mathrm{RH}_{\text {ice }}$ is described in the supplement (Fig. S3 in the Supplement). Above the upper bound of $10^{12} \mathrm{~m}^{-2}, n_{\mathrm{s}}$ presumably remains constant up to the water saturation line in the $T$ and $\mathrm{RH}_{\text {ice }}$ space (no experimental data is available in this range). This assumption is valid in the present study because this $n_{\mathrm{s}}$ upper limit was hardly reached in our modeling case. However, more cloud simulation chamber measurements and data points for $n_{\mathrm{s}} \gg 10^{12} \mathrm{~m}^{-2}$ are required to correctly constrain the $n_{\mathrm{s}}$ upper limit. It also has to be noted that the modeled ice crystal number concentration $\left(L^{-1}\right)$ derived from ice nucleation of hematite in this study is approximated by multiplying $n_{\mathrm{S}}$ by a simulated total surface of hematite $\left(6.3 \times 10^{-10} \mathrm{~m}^{2} \mathrm{~L}^{-1}\right)$.

In the second fit approach (Fig. 4b), the interpolated $n_{\mathrm{S}}$ values were used to formulate the $n_{\mathrm{s}}$-isoline with a third-degreepolynomial fit as a function of $T\left({ }^{\circ} \mathrm{C}\right)$ and $\mathrm{RH}_{\text {ice }}(\%)$ as

$$
\begin{aligned}
& n_{\mathrm{s}}^{3 d}\left(T, \mathrm{RH}_{\mathrm{ice}}\right)=-3.777 \times 10^{13}-7.818 \times 10^{11} \\
& \cdot T+4.252 \times 10^{11} \cdot \mathrm{RH}_{\mathrm{ice}}-4.598 \times 10^{9} \cdot T^{2}+6.952 \times 10^{9} \\
& \cdot T \cdot \mathrm{RH}_{\mathrm{ice}}-1.111 \times 10^{9} \cdot \mathrm{RH}_{\mathrm{ice}}^{2}-2.966 \times 10^{6} \cdot T^{3} \\
& +2.135 \times 10^{7} \cdot T^{2} \cdot \mathrm{RH}_{\mathrm{ice}}-1.729 \times 10^{7} \cdot T \cdot \mathrm{RH}_{\mathrm{ice}}^{2} \\
& -9.438 \times 10^{5} \cdot \mathrm{RH}_{\text {ice }}^{3} \\
& \text { for }-78^{\circ} \mathrm{C}<T<-36^{\circ} \mathrm{C} \text { and } \\
& 100 \%<\mathrm{RH}_{\text {ice }}<\text { water saturation, }
\end{aligned}
$$

where $n_{\mathrm{s}}^{3 \mathrm{~d}}\left(T, \mathrm{RH}_{\mathrm{ice}}\right)$ is the $n_{\mathrm{s}}$ derived from the third-degree fit. The resulting spatial plot of isolines for constant $n_{\mathrm{s}}$ is shown in Fig. 4b. Note that the upper temperature boundary of $-36^{\circ} \mathrm{C}$ was assigned as the interface between immersionmode and deposition-mode ice nucleation (Hiranuma et al., 2014), and the lower boundary of $-78^{\circ} \mathrm{C}$ is the limit introduced by interpolating the hematite-isoline curves. The third approach (Fig. 4c) consisted in applying the equivalent $n_{\mathrm{s}}$ for deposition nucleation of hematite particles parameterized using the method introduced by Phillips et al. $(2008,2013)$. 


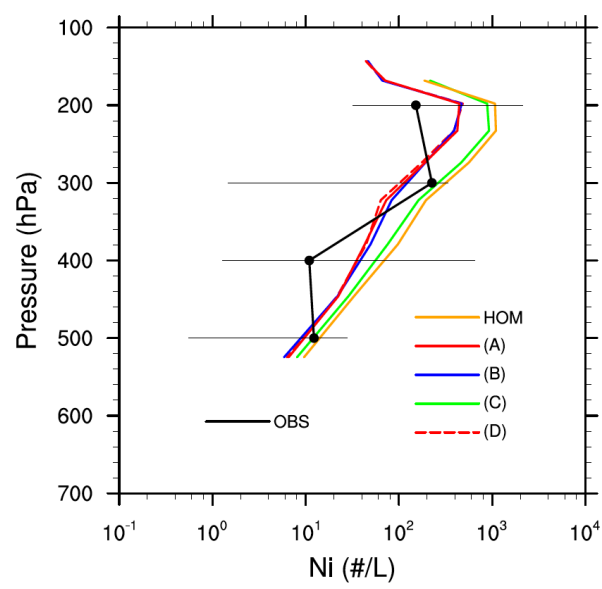

Figure 5. Monthly mean profiles of the simulated in-cloud ice crystal number concentrations $\left(N i \sim N_{\text {ice }}\right)$ over the ARM SGP site. The four cases shown in the figure include the pure homogeneous ice nucleation case (HOM) and four combined (heterogeneous + homogeneous) ice nucleation cases: (a) AIDA interpolated +homogeneous; (b) AIDA fit + homogeneous; (c) P13 + homogeneous; and (d) AIDA interpolated $\left(\mathrm{RH}_{\mathrm{i}}^{*}=105 \%\right)+$ homogeneous. Black dots show the observed mean profile of $\mathrm{Ni}$. Left and right ends of the horizontal bars indicate the 10th and 90th percentiles of the observed $\mathrm{Ni}$ values at each pressure level.

Specifically, we characterized the nucleation activity solely of mineral dust through the deposition-mode by adapting Eq. (1) from Phillips et al. (2008), which accounts for nucleation under water subsaturated conditions, and excluded the contribution at water saturation, i.e., Eq. (2) of Phillips et al. (2008). AIDA $n_{\mathrm{s}}$-isoline-based parameterization suggests strong supersaturation dependence of $n_{\mathrm{s}}$ at low $T$. Observed diversity between a new parameterization (Fig. 4a, b) and P13 (Fig. 4c) may result in different ice crystal forming propensities and may predict different cloud properties. The potential consequence of observed diversity is demonstrated using conceptual models and discussed in the following section.

\subsection{Model simulations}

The SCAM5 results for monthly mean profiles of the simulated in-cloud $N_{\text {ice }}\left(N i \sim N_{\text {ice }}\right)$ over the ARM SGP site for five cases are shown in Fig. 5. These include (case 1) the pure homogeneous ice nucleation case, (cases 2-4) cases with contributions from both homogeneous and heterogeneous ice nucleation (hereinafter referred to as the combined cases) described in Fig. 4a-c (corresponding to simulations A, B and $\mathrm{C}$ ), and (case 5) the simulation of the different lower boundaries of $\mathrm{RH}_{\text {ice }}\left(\mathrm{RH}_{\mathrm{i}}^{*}\right.$, simulation $\left.\mathrm{D}\right)$. In addition, the observed profile of ice crystal number concentrations is also shown in comparison to the simulations in Fig. 5. The observational data were collected over the SGP site on 8 days of April 2010

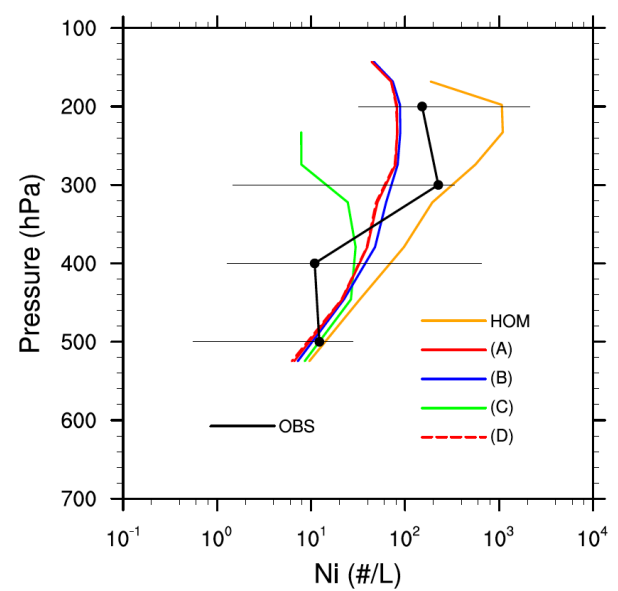

Figure 6. Monthly mean profiles of the simulated in-cloud ice crystal number concentrations $\left(N i \sim N_{\text {ice }}\right)$ over the ARM SGP site. The four cases shown in the figure include the pure homogeneous ice nucleation case (HOM) and four pure heterogeneous ice nucleation cases: (a) AIDA interpolated; (b) AIDA fit; (c) P13; and (d) AIDA interpolated $\left(\mathrm{RH}_{\mathrm{i}}^{*}=105 \%\right)$. Black dots show the observed mean profile of Ni. Left and right ends of the horizontal bars indicate the 10th and 90th percentiles of the observed $N i$ values at each pressure level.

during the Small Particles In Cirrus (SPARTICUS) campaign (Zhang et al., 2013). The results of our simulations suggests that ice crystal formation due to heterogeneous ice nucleation processes inhibits homogeneous ice nucleation and significantly reduces the ice number concentrations for the AIDA parameterizations (Fig. 4a, b). In contrast, due to the much less ice crystal production from P13, as shown by the pure heterogeneous case in Fig. 5, homogeneous ice nucleation in the P13 case (Fig. 4c) is less affected by heterogeneous nucleation. The observed mean profile of in-cloud ice crystal number concentrations is in agreement with the simulated ones. The differences between the three parameterizations derived from AIDA measurements, corresponding to simulations A, B and D, are small for both the combined case and the pure heterogeneous ice nucleation case as presented in Fig. 6. This is because the BN scheme used in SCAM5 is based on parcel model theory and uses the predicted maximum ice supersaturation $\left(S_{\max }\right)$ to calculate deposition ice nucleation rates. $S_{\max }$ is determined by assuming that the supersaturation will reach its maximum where the depletion of water vapor compensates the supersaturation increase from cooling in a cloud parcel (i.e., BN scheme). The three parameterizations (i.e., simulations $\mathrm{A}, \mathrm{B}$ and $\mathrm{D}$ ) have the largest differences when $\mathrm{RH}_{\text {ice }}$ is below $120 \%$ while $S_{\max }$ calculated in the model is often larger than $115 \%$. This also explains the low sensitivity of $N_{\text {ice }}$ to the lower bound of the onset $\mathrm{RH}_{\text {ice }}$ value (Figs. 5, 6). We also investigated the impact of different particle size distributions on the calculation (not shown). The impact is small and negligible. The negligible sensitivity to the choice of AIDA parameterizations in SCAM5 simula- 


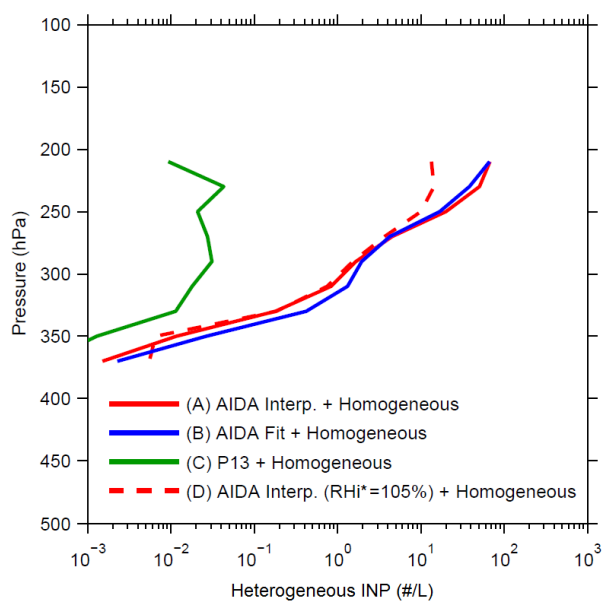

Figure 7. The mean heterogeneous INP number concentrations $\left(\sim N_{\text {ice }}\right)$ simulated in COSMO. The red dashed line represents the simulation with $105 \% \mathrm{RH}_{\text {ice }}$ as the lower boundary of ice formation, while the others are based on with $100 \%$ for the minimum $\mathrm{RH}_{\text {ice }}$ value.

tions (simulations A and B of Figs. 5 and 6) as well as the negligible sensitivity to the lower bound of the $\mathrm{RH}_{\text {ice }}$ value for ice nucleation, $\mathrm{RH}_{\mathrm{i}}^{*}$ in Figs. 5 and 6, reflect the limitation of SCAM5 as a large-scale model, which cannot explicitly resolve the subgrid (for the GCM grid box) variability of the supersaturation.

The results of the COSMO model for the vertical profiles of $N_{\text {ice }}$ (presumably equivalent to the heterogeneous INP number concentration) are summarized in Fig. 7. These results simulate the three different parameterization schemes (corresponding to Fig. 4a-c) in combination with homogeneous freezing. $N_{\text {ice }}$ was spatially averaged over all areas of the model domain which in principle allow for deposition nucleation in our simulations, i.e., conditions below $-36^{\circ} \mathrm{C}$ and above $100 \% \mathrm{RH}_{\text {ice. }}$. Because $n_{\mathrm{s}}$ is not always larger than the lower bound of the $n_{\mathrm{s}}$ value $\left(10^{6} \mathrm{~m}^{-2}\right.$, i.e., white areas in Fig. 4), also areas without ice formation are contained. It is also noteworthy that only purely heterogeneous ice formation is presented rather than the total ice occurring in the model. As shown in Fig. 7, the mean $N_{\text {ice }}$ resulting from the parameterization based on P13 is smaller than that obtained from the AIDA $n_{\mathrm{s}}$-isoline-based parameterization by more than 2 orders of magnitude. This large difference results predominantly from the inactivity of $\mathrm{P} 13$ at low $\mathrm{RH}_{\text {ice. }}$. Unlike the SCAM5 results, the COSMO results show the sensitivity to the different lower boundaries of $\mathrm{RH}_{\text {ice }}$ (i.e., $\mathrm{RH}_{\mathrm{i}}^{*}=105 \%$, simulation D). For instance, the mean $N_{\text {ice }}$ below $-36^{\circ} \mathrm{C}$ with a higher $\mathrm{RH}_{\text {ice }}$ boundary $(105 \%)$ is reduced by $12 \%$. This difference is perhaps due to the use of finely resolved grid-scale humidity in COSMO rather than parameterizing $S_{\max }$ as done in SCAM5 (Gettelman et al., 2010). Figure 8 illustrates the differences between P13 and the AIDA results depending on $T$ and $\mathrm{RH}_{\text {ice }}$. Simulated $N_{\text {ice }}$ values are segre-
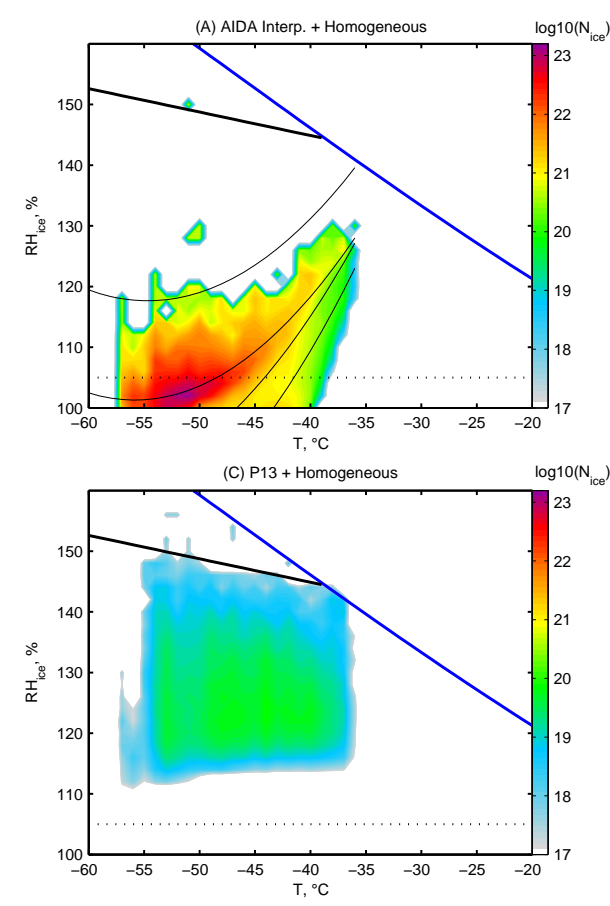

Figure 8. Accumulated ice crystal concentrations (color scale in total crystals per model domain) as a function of temperature $\left(1^{\circ} \mathrm{C}\right.$ bins) and $\mathrm{RH}_{\text {ice }}(2 \%$ bins). Heterogeneous nucleation simulated by AIDA parameterization (i.e., Fig. 4a) and P13 parameterization (i.e., Fig. 4c) was combined with homogeneous nucleation of cloud droplets.

gated in fine $T$ and $\mathrm{RH}_{\text {ice }}$ spacing $(1 \mathrm{~K}$ and $2 \%$ bins, respectively) based on the thermodynamic conditions under which ice crystals were formed in COSMO and summed up over the time of simulation. This segregation allows for an estimation of the relative contribution of different thermodynamic conditions to the simulated ice formation. Our results show diversity between P13 and the AIDA $n_{\mathrm{s}}$-isoline-based parameterization. Ice crystal formation was less for P13 and more for the new parameterization. A possible explanation for the observed deviation may be due to the difference in parameterization based on laboratory or field data. For instance, atmospheric aging and processing (i.e., surface coating and associated heterogeneous surface reactions) may have altered ice nucleating propensity and limited deposition nucleation of dust-derived INPs in the P13 parameterization for the field data-derived parameterization as discussed in Phillips et al. (2008).

\section{Discussions}

As described in the previous section (Sect. 3.1), depositionmode freezing cannot solely explain the $n_{\mathrm{s}}$-isoline observation below water saturation $\left(-50^{\circ} \mathrm{C}<\mathrm{T}<-36^{\circ} \mathrm{C}\right.$ in Fig. 2). Although we presumed that $\mathrm{SCF}$ acts as a subset of immer- 
sion freezing and plays an important role in this region, further insight and evidence of SCF beyond cloud simulation chamber observations are required to correctly understand the contributions of both homogeneous and heterogeneous nucleation. High-resolution microscopic techniques with an integrated continuous cooling setup are needed to visualize the freezing process of a single particle and to fully understand the complex freezing processes involved in SCF on particle surfaces.

Comparison of the new parameterization to a previous empirical parameterization (P13) showed that the new AIDA $n_{\mathrm{S}^{-}}$ isoline-based scheme predicts more ice (Figs. 4-8). In particular, the $T$ and $\mathrm{RH}_{\text {ice }}$ dependence of $N_{\text {ice }}$ and $n_{\mathrm{s}}$ at low $T$ that may coincide in the upper troposphere highlights the need for further investigations. However, it should be noted that there is some evidence for the atmospheric relevance and applicability of the new parameterization. First of all we demonstrated that the new $n_{\mathrm{s}}$ parameterization based on the experiments with hematite particles agrees well with previous literature results for mineral dust aerosol (e.g., Möhler et al., 2006; Welti et al., 2009; Koehler et al., 2010). Second, Niemand et al. (2012) demonstrated that different dusts exhibit similar $n_{\mathrm{s}}$ in immersion-mode freezing and perhaps such a similarity remains true for the deposition-mode ice nucleation of desert dusts. Lastly, the comparison between the observed profile of ice crystal number concentrations and the simulated ones (Figs. 5, 6) also suggests the validity of the new parameterization. These premises must be further examined in comparing to atmospherically relevant substrates (fresh and aged ones) and their ice nucleation activities in laboratory settings. In situ INP measurements, such as the number concentration and the types of INPs, at the upper troposphere can also help to constrain the parameterization.

Finally, to further develop more atmospherically relevant parameterizations other than the fit-based parameterization with artificial test aerosol, the relationship between $1 / T$ and $\ln S_{\text {ice }}$ for a constant nucleation rate or $n_{\mathrm{s}}$ based on the CNT can be analyzed (i.e., Eqs. A10-A11 in Hoose and Möhler, 2012). In this way, the composition-specific $n_{\mathrm{S}}\left(T-S_{\text {ice }}\right)$ values, where the transition from SCF to deposition nucleation (or vice versa) occurs, may be better defined and can be then be used as an inexpensive model friendly parameterization.

\section{Conclusion}

A new heterogeneous ice nucleation parameterization was developed using results obtained from AIDA cloud simulation chamber experiments. The new $n_{\mathrm{s}}$-isoline-based parameterization is applicable to a wide temperature range from -36 to $-78^{\circ} \mathrm{C}$ and, hence, allows for the examination of ice nucleation spectra in a simple framework for modeling application.
Our experimental results provide a good basis for the $T$ and $\mathrm{RH}_{\mathrm{ice}}$ dependence of deposition nucleation, and the formulated hematite $n_{\mathrm{s}}$ isolines are comparable to that of desert dust samples. Consequently, our results with synthesized hematite particles can also be relevant to cirrus applications despite their smaller atmospheric relevance compared to natural hematite. Our isoline formulation suggested three different ice nucleation pathways over the wide range of temperature. Specifically, a $\mathrm{RH}_{\text {ice }}$-dependent ice nucleation regime was observed at temperatures below $\sim-60^{\circ} \mathrm{C}$, where deposition mode is presumably responsible for triggering ice nucleation. At $-60{ }^{\circ} \mathrm{C}<T<-50{ }^{\circ} \mathrm{C}$, ice nucleation efficiency

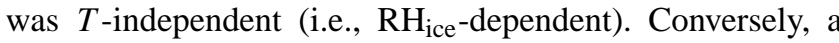
predominant influence of $T$ on ice nucleation was observed near the water saturation condition $\left(T>\sim-50^{\circ} \mathrm{C}\right)$, which may be indicative of nucleation due to condensation of water at the particle surface followed by homogeneous freezing of the condensed water (i.e., SCF). The observed active SCF near water saturation and physical processes at the transitions of nucleation modes still remain to be studied in detail for various types of atmospheric particles.

Our conceptual model examinations also considered the competition between heterogeneous freezing and homogeneous freezing of solution particles to evaluate the relative importance of the different freezing processes in two models (SCAM5 and COSMO). The inhibition of homogeneous nucleation due to heterogeneous freezing was commonly observed in both SCAM5 and COSMO simulations. Our new parameterization revealed a minimum deviation of $N_{\text {ice }}$ values estimated by SCAM5 at minimum $\mathrm{RH}_{\text {ice }}$ values for ice formation (100 or $105 \%$ ) compared to COSMO. This deviation suggests different sensitivities of the model to the lower bound of the $\mathrm{RH}_{\text {ice }}$ value owing to the presence of the modelresolved supersaturation to calculate the ice nucleation rate. Overall, our new hematite-based parameterization strongly suggests the role of $T$ and more ice nucleation when compared to the existing empirical parameterization, presumably allowing for more ice activation under water subsaturated conditions.

\section{The Supplement related to this article is available online at doi:10.5194/acp-14-13145-2014-supplement.}

Author contributions. N. Hiranuma and O. Möhler designed and conceived the experiments. Parameterizations were implemented by N. Hiranuma, I. Steinke and M. Paukert. M. Paukert and K. Zhang carried out modeling studies with input from C. Hoose, N. Hiranuma and G. Kulkarni. M. Schnaiter analyzed SIMONE data. H. Saathiff contributed to TDL measurements and analysis. The manuscript was written by N. Hiranuma. All authors discussed the results and contributed ideas to the manuscript. 
Acknowledgements. This work was supported by the German Research Foundation (Deutsche Forschungsgemeinschaft, DfG) under contracts MO 668/4-1 and HO 4612/1-1 within the Research Unit FOR 1525 (INUIT) and by the Helmholtz Association's research programme Atmosphere and Climate (ATMO). The authors acknowledge partial financial support by DfG and the Open Access Publishing Fund of Karlsruhe Institute of Technology. K. Zhang and G. Kulkarni acknowledge support from the Department of Energy Atmospheric System Research Program. The Pacific Northwest National Laboratory is operated for DOE by Battelle Memorial Institute under contract DE-AC05-76RLO 1830. We would like to thank R. Buschbacher, T. Chudy, O. Dombrowski, E. Kranz, G. Scheurig and S. Vogt for their professional support for the AIDA chamber operation during the INUIT campaigns. We also thank P. Weidler and S. Jaeger for support in preparing the hematite particles. M. Hummel's contribution to the model setup is gratefully acknowledged.

The service charges for this open access publication

have been covered by a Research Centre of the

Helmholtz Association.

Edited by: D. J. Cziczo

\section{References}

Archuleta, C. M., DeMott, P. J., and Kreidenweis, S. M.: Ice nucleation by surrogates for atmospheric mineral dust and mineral dust/sulfate particles at cirrus temperatures, Atmos. Chem. Phys., 5, 2617-2634, doi:10.5194/acp-5-2617-2005, 2005.

Baldauf, M., Seifert, A., Förstner, J., Majewski, D., Raschendorfer, M., and Reinhardt, T.: Operational convective-scale numerical weather prediction with the COSMO model: Description and sensitivities, Mon. Weather Rev., 139, 12, 3887-3905, doi:10.1175/MWR-D-10-05013.1, 2011.

Barahona, D. and Nenes, A.: Parameterization of cirrus cloud formation in large-scale models: Homogeneous nucleation, J. Geophys. Res., 113, D11211, doi:10.1029/2007JD009355, 2008.

Barahona, D. and Nenes, A.: Parameterizing the competition between homogeneous and heterogeneous freezing in cirrus cloud formation - monodisperse ice nuclei, Atmos. Chem. Phys., 9, 369-381, doi:10.5194/acp-9-369-2009, 2009a.

Barahona, D. and Nenes, A.: Parameterizing the competition between homogeneous and heterogeneous freezing in ice cloud formation - polydisperse ice nuclei, Atmos. Chem. Phys., 9, 59335948, doi:10.5194/acp-9-5933-2009, 2009b.

Barahona, D., Rodriguez, J., and Nenes, A.: Sensitivity of the global distribution of cirrus ice crystal concentration to heterogeneous freezing, J. Geophys. Res., 115, D23213, doi:10.1029/2010JD014273, 2010.

Benz, S., Megahed, K., Möhler, O., Saathoff, H., Wagner, R., and Schurath, U.: $T$-dependent rate measurements of homogeneous ice nucleation in cloud droplets using a large atmospheric simulation chamber, J. Photochem. Photobiol. A, 176, 208-217, doi:10.1016/j.jphotochem.2005.08.026, 2005.

Boucher, O., Randall, D., Artaxo, P., Bretherton, C., Feingold, G., Forster, P., Kerminen, V.-M., Kondo, Y., Liao, H., Lohmann, U., Rasch, P., Satheesh, S. K., Sherwood, S., Stevens, B., and Zhang,
X. Y.: Clouds and Aerosols. In: Climate Change 2013: The Physical Science Basis. Contribution of Working Group I to the Fifth Assessment Report of the Intergovernmental Panel on Climate Change, edited by: Stocker, T. F., Qin, D., Plattner, G.-K., Tignor, M., Allen, S. K., Boschung, J., Nauels, A., Xia, Y., Bex, V., and Midgley, P. M., Cambridge University Press, Cambridge, UK and New York, NY, USA, 571-657, 2013.

Christenson, H.: Two-step crystal nucleation via capillary condensation, Cryst. Eng. Comm., 15, 2030-2039, doi:10.1039/C3CE26887J, 2013.

Claquin, T., Schulz, M., and Balkanski, Y.: Modeling the mineralogy of atmospheric dust sources, J. Geophys. Res., 104, 2224322256, doi:10.1029/1999JD900416, 1999.

Connolly, P. J., Möhler, O., Field, P. R., Saathoff, H., Burgess, R., Choularton, T., and Gallagher, M.: Studies of heterogeneous freezing by three different desert dust samples, Atmos. Chem. Phys., 9, 2805-2824, doi:10.5194/acp-9-2805-2009, 2009.

Cziczo, D. J. and Froyd, K. D.: Sampling the composition of cirrus ice residuals, Atmospheric Research, 142, 15-31, doi:10.1016/j.atmosres.2013.06.012, 2014.

Cziczo, D. J., Froyd, K. D., Hoose, C., Jensen, E. J., Diao, M., Zondlo, M. A., Smith J. B., Twohy, C. H., and Murphy, D. M.: Clarifying the dominant sources and mechanisms of cirrus cloud formation, Science, 340, 1320-1324, doi:10.1126/science.1234145, 2013.

DeMott, P. J., Möhler, O., Stetzer, O., Vali, G., Levin, Z., Petters, M. D., Murakami, M., Leisner, T., Bundke, U., Klein, H., Kanji, Z. A., Cotton, R., Jones, H., Benz, S., Brinkmann, M., Rzesanke, D., Saathoff, H., Nicolet, M., Saito, A., Nillius, B., Bingemer, H., Abbatt, J., Ardon, K., Ganor, E., Georgakopoulos, D. G., and Saunders, C.: Resurgence in ice nuclei measurement research, B. Am. Meterol. Soc., 92, 1623-1625, doi:10.1175/2011BAMS3119.1, 2011.

Doms, G., Förster, J., Heise, E., Herzog, H.-J., Mironov, D., Raschendorfer, M., Reinhardt, T., Ritter, B., Schrodin, R., Schulz, J.-P., and Vogel, G.: A description of the nonhydrostatic regional COSMO Model. Part II: Physical parameterization, Technical Report, Deutscher Wetterdienst, 154 pp., 2011.

Fahey, D. W., Gao, R.-S., Möhler, O., Saathoff, H., Schiller, C., Ebert, V., Krämer, M., Peter, T., Amarouche, N., Avallone, L. M., Bauer, R., Bozóki, Z., Christensen, L. E., Davis, S. M., Durry, G., Dyroff, C., Herman, R. L., Hunsmann, S., Khaykin, S. M., Mackrodt, P., Meyer, J., Smith, J. B., Spelten, N., Troy, R. F., Vömel, H., Wagner, S., and Wienhold, F. G.: The AquaVIT-1 intercomparison of atmospheric water vapor measurement techniques, Atmos. Meas. Tech., 7, 3177-3213, doi:10.5194/amt-7-3177-2014, 2014.

Gettelman, A., Hegglin, M. I., Son, S.-W., Kim, J., Fujiwara, M., Birner, T., Kremser, S., Rex, M., Añel, J. A., Akiyoshi, H., Austin, J., Bekki, S., Braesike, P., Brühl, C., Butchart, N., Chipperfield, M., Dameris, M., Dhomse, S., Garny, H., Hardiman, S. C., Jöckel, P., Kinnison, D. E., Lamarque, J. F., Mancini, E., Marchand, M., Michou, M., Morgenstern, O., Pawson, S., Pitari, G., Plummer, D., Pyle, J.A., Rozanov, E., Scinocca, J., Shepherd, T. G., Shibata, K., Smale, D., Teyssèdre, H., and Tian, W.: Multimodel assessment of the upper troposphere and lower stratosphere: Tropics and global trends, J. Geophys. Res., 115, D00M08, doi:10.1029/2009JD013638, 2010. 
Hiranuma, N., Hoffmann, N., Kiselev, A., Dreyer, A., Zhang, K., Kulkarni, G., Koop, T., and Möhler, O.: Influence of surface morphology on the immersion mode ice nucleation efficiency of hematite particles, Atmos. Chem. Phys., 14, 2315-2324, doi:10.5194/acp-14-2315-2014, 2014.

Hoose, C. and Möhler, O.: Heterogeneous ice nucleation on atmospheric aerosols: a review of results from laboratory experiments, Atmos. Chem. Phys., 12, 9817-9854, doi:10.5194/acp-12-98172012, 2012.

Hoose, C., Kristjánsson, J. E., Chen, J.-P., and Hazra, A.: A classical-theory-based parameterization of heterogeneous ice nucleation by mineral dust, soot and biological particles in a global climate model, J. Atmos. Sci., 67, 2483-2503, doi:10.1175/2010JAS3425.1, 2010.

Hung, H.-M., Malinowski, A., and Martin, S. T.: Kinetics of heterogeneous ice nucleation on the surfaces of mineral dust cores inserted into aqueous ammonium sulfate particles, J. Phys. Chem. A., 107, 1296-1306, doi:10.1021/jp021593y, 2003.

Kärcher, B. and Lohmann, U.: A parameterization of cirrus cloud formation: Heterogeneous freezing, J. Geophys. Res., 108, 4402, doi:10.1029/2002JD003220, 2003.

Kärcher, B., Hendricks, J., and Lohmann, U.: Physically based parameterization of cirrus cloud formation for use in global atmospheric models, J. Geophys. Res., 111, D01205, doi:10.1029/2005JD006219, 2006.

Khvorostyanov, V. I. and Curry, J. A.: The theory of ice nucleation by heterogeneous freezing of deliquescent mixed CCN. Part I: Critical radius, energy, and nucleation rate, J. Atmos. Sci., 61, 2676-2691, doi:10.1175/JAS3266.1, 2004.

Koehler, K. A., Kreidenweis, S. M., DeMott, P. J., Petters, M. D., Prenni, A. J., and Möhler, O.: Laboratory investigations of the impact of mineral dust aerosol on cold cloud formation, Atmos. Chem. Phys., 10, 11955-11968, doi:10.5194/acp10-11955-2010, 2010.

Koop, T., Luo, B., Tsias, A., and Peter, T.: Water activity as the determinant for homogeneous ice nucleation in aqueous solutions, Nature, 406, 611-614, doi:10.1038/35020537, 2000.

Liu, X. and Penner, J. E.: Ice nucleation parameterization for global models, Meteorol. Z., 14, 499-514, doi:10.1127/09412948/2005/0059, 2005.

Liu, X., Shi, X., Zhang, K., Jensen, E. J., Gettelman, A., Barahona, D., Nenes, A., and Lawson, P.: Sensitivity studies of dust ice nuclei effect on cirrus clouds with the Community Atmosphere Model CAM5, Atmos. Chem. Phys., 12, 12061-12079, doi:10.5194/acp-12-12061-2012, 2012.

Marcolli, C.: Deposition nucleation viewed as homogeneous or immersion freezing in pores and cavities, Atmos. Chem. Phys., 14, 2071-2104, doi:10.5194/acp-14-2071-2014, 2014.

Matsuki, A., Schwarzenboeck, A., Venzac, H., Laj, P., Crumeyrolle, S., and Gomes, L.: Cloud processing of mineral dust: direct comparison of cloud residual and clear sky particles during AMMA aircraft campaign in summer 2006, Atmos. Chem. Phys., 10, 1057-1069, doi:10.5194/acp-10-1057-2010, 2010.

Meyers, M. P., DeMott, P. J., and Cotton, W. R.: New primary ice nucleation parameterizations in an explicit cloud model, J. Appl. Meteorol., 31, 708-721, doi:10.1175/15200450(1992)031<0708:NPINPI>2.0.CO;2, 1992.

Möhler, O., Stetzer, O., Schaefers, S., Linke, C., Schnaiter, M., Tiede, R., Saathoff, H., Krämer, M., Mangold, A., Budz, P., Zink,
P., Schreiner, J., Mauersberger, K., Haag, W., Kärcher, B., and Schurath, U.: Experimental investigation of homogeneous freezing of sulphuric acid particles in the aerosol chamber AIDA, Atmos. Chem. Phys., 3, 211-223, doi:10.5194/acp-3-211-2003, 2003.

Möhler, O., Linke, C., Saathoff, H., Schnaiter, M.,Wagner, R., Mangold, A., Krämer, M., and Schurath, U.: Ice nucleation on flame soot aerosol of different organic carbon content, Meteorol. Z., 14, 477-484, doi:10.1127/0941-2948/2005/0055, 2005.

Möhler, O., Field, P. R., Connolly, P., Benz, S., Saathoff, H. Schnaiter, M., Wagner, R., Cotton, R., Krämer, M., Mangold, A., and Heymsfield, A. J.: Efficiency of the deposition mode ice nucleation on mineral dust particles, Atmos. Chem. Phys., 6, 30073021, doi:10.5194/acp-6-3007-2006, 2006.

Murray, B. J., O'Sullivan, D., Atkinson, J. D., and Webb, M. E.: Ice nucleation by particles immersed in supercooled cloud droplets, Chem. Soc. Rev., 41, 6519-6554, doi:10.1039/c2cs35200a, 2012.

Neale, R. B., Chen, C-.C., Gettelman , A., Lauritzen, P. H., Park, S., Williamson, D. L., Conley, A. J., Garcia, R., Kinnison, D., Lamarque, J-.F., Marsh, D., Mills, M., Smith, A. K., Tilmes, S., Vitt, F., Morrison, H., Cameron-Smith, P., Collins, W. D., Iacono, M. J., Easter, R. C., Ghan, S. J., Liu, X., Rasch, P. J., and Taylor, M. A.: Description of the NCAR Community Atmosphere Model (CAM5.0), Tech. Rep. NCAR/TN-486-STR, NCAR, available at: http://www.cesm.ucar.edu/models/cesm1.0/ cam/ (last access: 8 January 2013), 2010.

Niemand, M., Möhler, O., Vogel, B., Vogel, H., Hoose, C., Connolly, P., Klein, H., Bingemer, H., DeMott, P., Skrotzki, J., and Leisner, T.: A particle-surface-area-based parameterization of immersion freezing on mineral dust particles, J. Atmos. Sci., 69, 3077-3092, doi:10.1175/JAS-D-11-0249.1, 2012.

Phillips, V. T. J., DeMott, P. J., and Andronache, C.: An empirical parameterization of heterogeneous ice nucleation for multiple chemical species of aerosol, J. Atmos. Sci., 65, 2757-2783, doi:10.1175/2007JAS2546.1, 2008.

Phillips, V. T. J., DeMott, P. J., Andronache, C., Pratt, K. A., Prather, K. A., Subramanian, R., and Twohy, C.: Improvements to an empirical parameterization of heterogeneous ice nucleation and its comparison with observations, J. Atmos. Sci., 70, 378-409, doi:10.1175/JAS-D-12-080.1, 2013.

Pruppacher, H. R. and Klett, J. D.: Microphysics of Clouds and Precipitation, Atmospheric and Oceanographic Sciences Library, Kluwer Academic Publishers, Dordrecht, The Netherlands, 309360, 1997.

Ren, C. and Mackenzie, A. R.: Cirrus parameterization and the role of ice nuclei, Q. J. Roy. Meteorol. Soc., 131, 1585-1605, doi:10.1256/qj.04.126, 2005.

Sakai, T., Orikasa, N., Nagai, T., Murakami, M., Tajiri, T., Saito, A., Yamashita, K., and Hashimoto, A.: Balloon-borne and Raman lidar observations of Asian dust and cirrus cloud properties over Tsukuba, Japan, J. Geophys. Res., 119, 3295-3308, doi:10.1002/2013JD020987, 2014.

Sassen, K. and Khvorostyanov, V. I.: Cloud effects from boreal forest fire smoke: Evidence for ice nucleation from polarization lidar data and cloud model simulations, Environ. Res. Lett., 3, 025006, doi:10.1088/1748-9326/3/2/025006, 2008.

Schnaiter, M., Büttner, S., Möhler, O., Skrotzki, J., Vragel, M., and Wagner, R.: Influence of particle size and shape on the 
backscattering linear depolarisation ratio of small ice crystals - cloud chamber measurements in the context of contrail and cirrus microphysics, Atmos. Chem. Phys., 12, 10465-10484, doi:10.5194/acp-12-10465-2012, 2012.

Seifert, A. and Beheng, K. D.: A two-moment cloud microphysics parameterization for mixed-phase clouds. Part I: Model description, Meteorol. Atmos. Phys., 92, 45-66, doi:10.1007/s00703005-0112-4, 2006.

Seifert, A., Köhler, C., and Beheng, K. D.: Aerosol-cloudprecipitation effects over Germany as simulated by a convectivescale numerical weather prediction model, Atmos. Chem. Phys., 12, 709-725, doi:10.5194/acp-12-709-2012, 2012.

Shilling, J. E., Fortin, T. J., and Tolbert, M. A.: Depositional ice nucleation on crystalline organic and inorganic solids, J. Geophys. Res., 111, D05207, doi:10.1029/2005JD006664, 2006.

Skrotzki, J., Connolly, P., Schnaiter, M., Saathoff, H., Möhler, O., Wagner, R., Niemand, M., Ebert, V., and Leisner, T.: The accommodation coefficient of water molecules on ice - cirrus cloud studies at the AIDA simulation chamber, Atmos. Chem. Phys., 13, 4451-4466, doi:10.5194/acp-13-4451-2013, 2013.

Steinke, I., Möhler, O., Kiselev, A., Niemand, M., Saathoff, H., Schnaiter, M., Skrotzki, J., Hoose, C., and Leisner, T.: Ice nucleation properties of fine ash particles from the Eyjafjallajökull eruption in April 2010, Atmos. Chem. Phys., 11, 12945-12958, doi:10.5194/acp-11-12945-2011, 2011.

Storelvmo, T. and Herger, N.: Cirrus cloud susceptibility to the injection of ice nuclei in the upper troposphere,J. Geophys. Res., 119, 2375-2389, doi:10.1002/2013JD020816, 2014.

Sugimoto, T. and Sakata, K.: Preparation of monodisperse pseudocubic $\alpha-\mathrm{Fe}_{2} \mathrm{O}_{3}$ particles from condensed ferric hydroxide gel, J. Colloid Interface Sci., 152, 587-590, doi:10.1016/00219797(92)90062-Q, 1992.
Vali, G.: Nucleation terminology, J. Aerosol Sci., 16, 575-576, doi:10.1016/0021-8502(85)90009-6, 1985.

Vragel, M.: Messung klimarelevanter optischer Eigenschaften von Mineralstaub im Labor, Faculty of Physics, Karlsruhe Institute of Technology, Karlsruhe, 162 pp., 2009.

Wang, B. and Knopf, D.: Heterogeneous ice nucleation on particles composed of humic-like substances impacted by $\mathrm{O}_{3}$, J. Geophys. Res., 116, D03205, doi:10.1029/2010JD014964, 2011.

Welti, A., Lüönd, F., Stetzer, O., and Lohmann, U.: Influence of particle size on the ice nucleating ability of mineral dusts, Atmos. Chem. Phys., 9, 6705-6715, doi:10.5194/acp-9-6705-2009, 2009.

Welti, A., Kanji, Z. A., Lüönd, F., Stetzer, O., and Lohmann, U.: Exploring the mechanisms of ice nucleation on kaolinite: from deposition nucleation to condensation freezing, J. Atmos. Sci., 71, 16-36, doi:10.1175/JAS-D-12-0252.1, 2014.

Zhang, K., Liu, X., Wang, M., Comstock, J. M., Mitchell, D. L., Mishra, S., and Mace, G. G.: Evaluating and constraining ice cloud parameterizations in CAM5 using aircraft measurements from the SPARTICUS campaign, Atmos. Chem. Phys., 13, 4963-4982, doi:10.5194/acp-13-4963-2013, 2013.

Zuberi, B., Bertram, A. K., Cassa, C. A., Molina, L. T., and Molina, M. J.: Heterogeneous nucleation of ice in $\left(\mathrm{NH}_{4}\right)_{2} \mathrm{SO}_{4}-\mathrm{H}_{2} \mathrm{O}$ particles with mineral dust immersions, Geophys. Res. Lett., 29, 1504, doi:10.1029/2001GL014289, 2002. 